\title{
Lisis de adherencias epidurales (Parte 2). Técnica intervencionista
}

\author{
G. Racz y J. C. Flores ${ }^{2}$ \\ ${ }^{I}$ Miembro Fundador del World Institute of Pain (WIP). Director del Centro de Medicina del Dolor de la UT \\ (Texas University). ${ }^{2}$ Chairman Latinamerican Training Center WFSA \& CLASA. Director CAIDBA \\ (Centro de Atención Integral del Dolor Buenos Aires)
}

Racz G. Flores JC. Lisis de adherencias epidurales (Parte 2). Técnica intervencionista. Rev Soc Esp Dolor 2013; 20(1): 16-24.

\begin{abstract}
This technique consists in the use of catheters and special needles to introduce solutions into difficult access sites in order to treat fibrosis or chronic inflammation conditions. Solutions such as hyaluronidase and hypertonic saline solution can be used for the lysis of adhesions caused by the pathology. This paper refers to different alternatives to correctly apply the technique at different spine levels. The technique has evolved from the conventional Tuhoy solution needles with some neurolitic properties to modern mapping needles and catheters that permit to position the desired solution at a distance, close to the desired root and/or foramen.

The most frequently affected area is the sacrolumbar segment, but different nosological entities that require clinical or surgical treatments may cause pain in the spinal canal, discs, vegetative structures or roots in any spinal segment. Many of these pathologies, most particularly after surgical treatments, cause inflammatory conditions and epidural adhesions that frequently lead to chronic pain. The pathophysiology and indication of this technique is developed in Part 1 of this publication.

This paper describes the techniques to perform lysis of adhesions at all spine levels. A thorough description is made of the caudal, lumbar, thoracic and cervical technique, the solutions administered, the catheters that are used in each case and physical therapy techniques for neural and epidural mapping. All techniques described are illustrated by an "Image gallery" for each procedure. The appropriate use of images is indicated with volume differences in each case. Tips for preventing complications are given.
\end{abstract}

\section{RESUMEN}

La técnica lisis de adherencias epidurales se basa en la introducción de catéteres a través de agujas especiales con una técnica determinada para permitir colocar soluciones en lugares de difícil acceso, con el objeto de resolver cuadros crónicos de fibrosis o inflamación. Las soluciones como hialuronidasa y solución fisiológica hipertónica principalmente permiten provocar la lisis de las adherencias resultantes de la patología. Se desarrollan en esta publicación las distintas alternativas para aplicar correctamente la técnica en los distintos niveles de la columna vertebral. La técnica ha evolucionado desde la inyección a través de agujas de Tuhoy convencionales de soluciones con alguna propiedad neurolítica hasta las modernas agujas y catéteres con mapeo que permiten posicionar a distancia la solución deseada cerca de la raíz y/o el foramen indicados.

Las dolencias y consultas médicas afectan más frecuentemente el segmento sacrolumbar pero las distintas entidades nosológicas, que derivan en tratamientos clínicos y quirúrgicos, pueden provocar dolor en el canal raquídeo, discos, estructuras vegetativas o en las raíces en cualquier segmento de la columna. Muchas de estas patologías especialmente después de tratamientos quirúrgicos provocan cuadros inflamatorios y adherencias epidurales, que evolucionan frecuentemente a cuadros de dolor crónico. Toda la fisiopatología e indicación de la presente técnica se desarrolla en la Parte 1 de esta publicación.

En esta publicación describimos las técnicas para realizar las técnicas de lisis de adherencias a todos los niveles de la columna vertebral. Se explica minuciosamente la técnica caudal, lumbar, torácica y cervical, las soluciones que se administran, que catéteres en cada caso, la técnicas kinesiológicas de frotado neural y el mapeo epidural. Todas las técnicas explicadas son acompañadas al final de la publicación por una "Galería de Imágenes". Se indica, el uso adecuado de las imágenes, las diferencias de volumen en cada caso, diagramas y posturas kinésicas recomendadas. Asimismo en cada caso se dan los tips para evitar las posibles complicaciones. 


\section{TÉCNICA}

Este procedimiento se puede realizar en las regiones cervical, torácica, lumbar o caudal de la columna. La ubicación caudal o transforaminal de catéteres serán descritas en detalle, mientras que se pondrán de relieve algunos detalles y cambios en el protocolo para los catéteres torácicos y cervicales. Los autores proponen realizar este procedimiento en sala de operaciones bajo estrictas condiciones de esterilidad. Se dan antibióticos profilácticos con cobertura amplia neuroaxial antes del procedimiento. Los pacientes recibirán ceftriaxona $1 \mathrm{~g}$ intravenoso o levofloxacina $500 \mathrm{mg}$ en forma oral en los alérgicos a la penicilina. Se repetirá la misma dosis el día post-procedimiento.

Siempre se contará con la asistencia de otro anestesiólogo que proveerá los cuidados anestésicos perioperatorios y conjuntamente se realizará el Check List de la OMS.

\section{Abordaje caudal}

Se utiliza la posición prona, con una almohada bajo el abdomen para corregir la lordosis lumbar y una almohada bajo los tobillos para su confort. Se solicita al paciente que ponga los dedos de los pies juntos y los talones separados. Esta maniobra relaja los músculos glúteos y facilita la identificación del hiato sacro. Luego de la esterilización y colocación de los campos, se identifica el hiato sacro por palpación justo en la zona caudal del cuerno sacro o con guía fluoroscópica. Se hace un habón de piel con anestésico local a una pulgada al costado y dos pulgadas en dirección caudal del hiato sacro, en el lado opuesto a la radiculopatía documentada.

En teoría, este abordaje distal o alejado daría cierta protección frente a la meningitis. Se debe cortar la piel con una aguja cortante calibre 18, y luego se inserta una aguja epidural calibre 15 o 16 RX Coude (Epimed International) a través del corte con un ángulo de 45 grados, con guía fluoroscópica o por palpación del hiato sacro. Cuando la aguja pasa a través del hiato, se disminuye el ángulo de la aguja a unos 30 grados aproximadamente, y luego se avanza. Las ventajas de la aguja RX Coude sobre las otras agujas son que tiene una punta angulada, que permite direccionar el catéter con más facilidad, y que la punta de la aguja no es tan afilada. El borde posterior del orificio distal de la aguja está diseñado para que sea una superficie roma, lo que permite la manipulación del catéter, entrando y saliendo de la aguja. La aguja Touhy tiene una superficie cortante en el borde posterior del agujero distal y por ello puede cortar el catéter fácilmente. La aguja debe colocase correctamente si está dentro del canal caudal por debajo del nivel del foramen S3 en las imágenes fluoroscópicas anteroposterior (AP) y lateral. Si la aguja estuviera ubicada por encima del nivel de foramen de S3, podría pinchar la duramadre cuando esta termina más distal. La punta de la aguja debería cruzar la línea media del sacro hacia el lado de la radiculopatía.

Se debe realizar un epidurograma usando $10 \mathrm{ml}$ de un agente de contraste no-iónico soluble en agua. Luego se debe confirmar la aspiración negativa de sangre o líquido cefalorraquídeo antes de la inyección del contraste o la medicación. Los agentes más usados son agentes no iónicos Omnipaque (iohexol), Optiray (ioversol) e Isovue (iopamidol), y son adecuados para la mielografía $(1,2)$. "No se deben utilizar agentes "iónicos" insolubles en agua" tales como Hypaque (diatrizoato de meglumina) o Renografin (diatrizoato) o agentes iónicos solubles en agua como el Conray $(3,4)$. Estos agentes iónicos "no están indicados para la mielografía" ya que en caso de inyección accidental en el espacio subaracnoideo pueden provocar eventos adversos serios tales como convulsiones e incluso la muerte. Se debe inyectar el contraste "lentamente" y observar si existen defectos de llenado. Un epidurograma normal tendrá un aspecto de "arbolito de Navidad", en el que el canal central es similar al tronco y el esquema de las raíces nerviosas representa las ramas. Un epidurograma anormal tendrá áreas donde el contraste no producirá llenado. Estas son las áreas donde se presumen cicatrices o fibrosis y se corresponde típicamente con las molestias radiculares del paciente. Si se observara reflujo o escape a través de vasos sanguíneos (run-off), la aguja deberá ser redireccionada.

Después de girar el orificio distal de la aguja hacia ventral y lateral, se debe insertar a través de la aguja un catéter tipo TunL Kath o TunL-XL (más rígido) (Epimed International) con una curva en la punta distal. La curva debe estar a $2,5 \mathrm{~cm}$ de la punta del catéter y con un ángulo de 30 grados. Esta curva permitirá que el catéter sea guiado al nivel deseado. Bajo control fluoroscópico AP continuo, se avanza la punta del catéter hacia el "espacio epidural ventral lateral" del nivel deseado. El catéter puede ser guiado mediante un suave giro en dirección de las agujas del reloj o en dirección contraria. Se debe evitar propulsar la punta (por ejemplo, girar la punta en forma circular) porque dificulta dirigir el catéter. No avanzar el catéter en el medio del sacro en la visión de Rx AP porque esto hará que sea más difícil guiar el catéter en el espacio lateral epidural.

La ubicación ideal de la punta del catéter en la proyección AP es el foramen, justo "bajo la porción media de la sombra del pedículo". Revisar la proyección lateral para confirmar que la punta del catéter está en el espacio epidural ventral.

Bajo fluoroscopía en tiempo real, inyectar 2 a $3 \mathrm{ml}$ de contraste adicional a través del catéter, intentando delinear la "fibrosis" en la raíz nerviosa. Si se nota reflujo vascular, se debe reposicionar el catéter y volver a inyectar contraste. No es conveniente que haya derrame vascular, pero con poca frecuencia, y secundariamente a la congestión venosa, se ve un patrón epidural con un pequeño derrame vascular. Esto será aceptable mientras sea un derrame de naturaleza 
Rev. Soc. Esp. del Dolor, Vol. 20, N. ${ }^{\circ}$ 1, Enero-Febrero 2013

venoso y no arterial. Se deberá tener mucho cuidado cuando se inyecta el anestésico local para prevenir la toxicidad anestésica. Cualquier escape de contraste en arterias obligará a un reposicionamiento del catéter. Nunca se observó en el Servicio del Dr Racz la colocación intra-arterial en 25 años utilizando catéteres con punta suave y elástica.

Se recomienda inyectar $1.500 \mathrm{U}$ de hialuronidasa disuelta en $10 \mathrm{ml}$ de solución salina sin conservantes. Es innovador el uso de Hylenex o hialuronidasa recombinante humana, que según se ha reportado, tiene la ventaja de tener mayor efectividad al $\mathrm{pH}$ normal del cuerpo, comparada con la hialuronidasa recombinante bovina (5). Esta inyección puede producir cierta molestia, de modo que se debe inyectar más lentamente. Se debe observar una "apertura" (mayor visualización) de la raíz nerviosa comprometida por la "fibrosis". Entonces se administra una dosis de prueba de $3 \mathrm{ml}$ de la dilución de $10 \mathrm{ml}$ del anestésico local + esteroide (AL/E). En el Servicio del Dr Racz se ha usado $4 \mathrm{mg}$ de dexametasona mezclados con $9 \mathrm{ml}$ de ropivacaína al $0,2 \%$. Se ha utilizado ropivacaína en vez de bupivacaína por dos razones: la primera es que produce mayor bloqueo sensitivo que motor, y es menos cardiotóxica que la bupivacaína racémica. Las dosis para los otros corticoides usados con frecuencia son: 40 a $80 \mathrm{mg}$ de metilprednisolona, 25 a $50 \mathrm{mg}$ de diacetato de triamcinolona, 40 a $80 \mathrm{mg}$ de acetónido de triamcinolona, y 6 a $12 \mathrm{mg}$ de betametasona. Si después de 5 minutos no hay evidencia de inyección de medicación intratecal o intravascular, se inyectan los $7 \mathrm{ml}$ remanentes de la solución AL/E.

Se debe remover la aguja bajo control fluoroscópico "continuo" para asegurarse de que el catéter se mantiene en el lugar deseado. Se debe fijar el catéter a la piel usando sutura no reabsorbible y se recubre la punción en la piel con crema antimicrobiana. Se aplica un vendaje estéril y se coloca un filtro de $0,2 \mathrm{~m}$ en el extremo del catéter. Se adhiere la parte expuesta del catéter al paciente con cinta y se traslada el paciente al área de recuperación.

Se debe esperar 20 a 30 minutos entre la última inyección de la solución de AL/E antes del comienzo de la infusión de solución salina hipertónica (10\%). Esto es necesario para asegurarse que la inyección de la solución de AL/E no ha sido subdural. Un bloqueo subdural remeda a uno subaracnoideo, pero lleva más tiempo en establecerse, en general de 16-18 minutos. El bloqueo motor es evidencia de la inyección o difusión al espacio subdural o subaracnoideo. Si el paciente desarrolla un bloqueo subdural o subaracnoideo en cualquier momento del procedimiento, se debe retirar el catéter y se deberá cancelar los pasos restantes de la liberación de adherencias. Se debe observar al paciente para confirmar la resolución del bloqueo motor y sensitivo, y para documentar que entonces se inyectaron $10 \mathrm{ml}$ de solución salina hipertónica a través del catéter en un periodo de 15 a 30 minutos. Si el paciente se queja de molestia, la infusión se deberá detener, se inyectarán 2 a $3 \mathrm{ml}$ de ropivacaína y luego se continúa con la infusión.
Alternativamente, se podrán inyectar 50 a $75 \mathrm{mg}$ de fentanilo epidural en lugar del anestésico local. Luego de completar la infusión de solución salina hipertónica, se lava lentamente el catéter con $2 \mathrm{ml}$ de solución salina normal sin conservantes, y se procede a cubrir el catéter.

Se recomienda admitir al paciente para observación durante 23 horas, y hacer una segunda y tercera infusión de solución salina hipertónica al día siguiente. En el día dos, después de la inserción del catéter, se le ha inyectado dos veces (a un intervalo de 4-6 horas) con $10 \mathrm{ml}$ de ropivacaína $0,2 \%$ sin esteroides, e infundido con $10 \mathrm{ml}$ de solución salina hipertónica (10\%) usando la misma técnica y precauciones de la infusión del primer día.

Al final de la tercera infusión, se retira el catéter y se aplica un vendaje estéril. Se da de alta al paciente con indicación de cefalexina $500 \mathrm{mg}$ vía oral por 5 días, dos veces por día, o levofloxacina $500 \mathrm{mg}$ vía oral una vez al día para los pacientes alérgicos a la penicilina. El seguimiento clínico será a los 30 días.

\section{Catéteres transforaminales}

Los pacientes con un nivel de radiculopatía adicional o aquellos en los que no se puede alcanzar el nivel deseado por el abordaje caudal, pueden requerir la colocación de un segundo catéter. El segundo catéter se coloca en el espacio epidural ventral, vía abordaje transforaminal.

Después de que se identifica el nivel deseado con una imagen fluoroscópica AP, se "encuadra" la placa terminal superior de la vértebra, que comprende la porción caudal del foramen, esto es, se superponen las sombras anterior y posterior de la placa terminal de la vértebra. Por lo general, el ángulo es de 15-20 grados en dirección céfalo-caudal. En este momento se coloca el fluoroscopio en posición oblicua, unos 15 grados hacia el lado de la radiculopatía y se ajusta hasta que se rota la apófisis espinosa hasta el lado opuesto.

Esta posición del fluoroscopio permite ver bien el proceso articular superior (PAS) que forma la porción inferoposterior del foramen respectivo. Se debe superponer la imagen del PAS sobre la sombra del disco en la vista oblicua. El objetivo es colocar la aguja en la punta del PAS. Se hace un habón de piel en dirección levemente lateral respecto de la sombra de la punta del PAS. Perfore la piel con una aguja calibre 18, y luego inserte otra aguja RX Coudé calibre 15 o 16. Avance hacia la punta del PAS usando la técnica del cargador de pistola o visión túnel. Continúe avanzando por el medio hacia el PAS, hasta llegar al hueso. Gire la punta de la aguja 180 grados lateralmente, y avance unos $5 \mathrm{~mm}$. Vuelva a girar la aguja 180 grados. Cuando la aguja avanza lentamente, se siente un "estallido" muy claro en el momento que la aguja penetra en el ligamento inter transverso. Se toma una imagen fluoroscópica lateral. La punta de la aguja debería estar en el foramen posterior, un poco más allá del 
PAS. Manteniéndose en el plano AP, bajo fluoroscopía continua, inserte el catéter lentamente en el foramen, y avance hasta que la punta casi llegue a la mitad del canal espinal. Confirmar mediante una imagen lateral, que el catéter está en el espacio epidural anterior. Anatómicamente, el catéter estará en el foramen superior o inferior de la raíz del nervio saliente. Si el catéter no avanza, generalmente se debe a que la aguja quedó muy posterior o muy lateral al foramen, o bien puede indicar un foramen demasiado estenótico que impide el paso del catéter. Se puede avanzar la aguja algunos milímetros en sentido anterior con respecto al foramen, de esta forma se consigue una posición más medial dentro del foramen. Si aún así no se consigue pasar el catéter, se debe reinsertar la aguja más lateralmente. En ese caso, el ángulo del fluoroscopio será de alrededor de 20 grados en lugar de 15 grados. Por lo general, la curva de la aguja ayuda a posicionar el catéter. El objetivo es lograr que la punta del catéter se sitúe casi en la línea media.

Se debe inyectar 1 a $2 \mathrm{ml}$ de sustancia de contraste para confirmar la dispersión epidural. Si se coloca un catéter caudal y otro transforaminal, las 1.500 unidades de hialuronidasa se deben dividir en partes iguales entre los dos (5 ml de hialuronidasa/solución salina para cada uno). La solución de AL/E también se reparte en partes iguales, pero en vez de $10 \mathrm{ml}$ se usa un volumen de $15 \mathrm{ml}$ ( $1 \mathrm{ml}$ de esteroides y $14 \mathrm{ml} \mathrm{0,2 \%}$ ropivacaína; del volumen total $5 \mathrm{ml}$ serán transforaminales y $10 \mathrm{ml}$ serán caudales). Se debe remover la aguja guiándose con el fluoroscopio para asegurarse que el catéter no cambie de posición en el espacio epidural. Asegure y recubra el catéter como se describió antes. Se realiza la infusión de solución salina hipertónica, un volumen de 4 a $5 \mathrm{ml}$ por el catéter transforaminal, y 8 a $10 \mathrm{ml}$ por el caudal, durante 30 minutos. El volumen de la solución salina hipertónica debe ser siempre menor o igual al volumen de anestésico utilizado, para evitar dolores causados por la inyección. Se debe chequear con el fluoroscopio la posición del catéter transforaminal antes de hacer la segunda y tercera infusión. Puede ocurrir que el catéter avance a través del espacio epidural, entrando en el foramen contralateral o los músculos paraespinales, o más comúnmente se salga del espacio epidural y entre en los músculos paraespinales ipsilaterales. Esto tiene como resultado que la medicación se deposite en el tejido paravertebral, en lugar del espacio epidural. Al igual que en el abordaje caudal, retire el catéter transforaminal después de la tercera infusión.

\section{Lisis cervical de adherencias}

El éxito del abordaje caudal para la lisis de adherencias condujo a que se aplicara la misma técnica en el espacio epidural cervical. Las indicaciones y análisis preoperatorios son los mismos que para la técnica caudal, pero hay algunas diferencias en cuanto al procedimiento y los volúmenes de medicación utilizados.
Se debe entrar al espacio epidural a través del espacio interlaminar, usando un abordaje paramedial contralateral. Los niveles más comunes son T1-2 y T2-3. Si se debe llegar a las raíces de los nervios cervicales inferiores, la entrada se hará por un espacio más caudal. Se puede colocar el paciente en una posición decúbito lateral izquierdo, pero se puede utilizar una posición prona en pacientes de mayor tamaño.

Para facilitar la entrada al espacio epidural, se utiliza una técnica conocida como "técnica 3-D". 3-D se refiere a dirección-profundidad (por la palabra Depth en inglés: dirección). Usando una imagen fluoroscópica AP, se determina la dirección inicial de la aguja RX Coudé (calibre 15 o 16). Usando un abordaje paramedial modificado, entrando por la piel un nivel y medio más abajo del espacio interlaminar a alcanzar, se avanza y dirige la aguja hacia el medio del espacio interlaminar elegido, con la abertura de la aguja apuntando en dirección medial. Una vez que la aguja pasa a la región de tejidos más profundos (normalmente a $2 \mathrm{o} 3 \mathrm{~cm}$ ), se debe verificar la profundidad de la aguja con una imagen lateral. Se avanza con la aguja hacia el espacio epidural y se vuelve a verificar la profundidad de la aguja con múltiples imágenes. El borde posterior del espacio epidural dorsal se puede identificar buscando la unión entre la base del proceso espinoso de la vértebra con su lámina. Esta unión genera una "línea recta" radio-opaca característica. Una vez que la aguja se encuentra cerca del espacio epidural, se revisa la imagen fluoroscópica AP para confirmar la dirección de la aguja. Si la punta de la aguja se encuentra más allá de la línea media definida por las apófisis espinosas de los cuerpos vertebrales, se debe retroceder y corregir la dirección. El proceso "3-D" se puede repetir cuantas veces sea necesario hasta ubicar la aguja exactamente en la posición deseaUsando la técnica de pérdida de resistencia, se introduce la aguja dentro del espacio epidural, con la punta de la RX Coudé en dirección caudal. Cuando la punta esté situada en el espacio epidural, se debe girar la punta en dirección cefálica, e inyectar 1 a 2 $\mathrm{ml}$ de sustancia de contraste para verificar la situación epidural. Cualquier giro o movimiento de la aguja en el espacio epidural puede cortar la duramadre. Esta técnica se ha beneficiado con el advenimiento de la aguja RX Coudé 2 , la cual cuenta con un estilete secundario, con un sistema de enclavamiento que sobresale un poco por la punta y ayuda a empujar la duramadre, separándola de la aguja mientras se gira 180 grados en dirección cefálica. Se recomienda inyectar un pequeño volumen adicional según sea necesario para completar el epidurograma. Si el contraste inyectado no fluye libremente, se puede producir un aumento de la presión en el espacio epidural lateral. Cuando el fluido se dispersa por el camino de menor resistencia, se conoce como DCV (dispersión contra venosa). La presencia de DCV se relaciona con un aumento de la presión en el espacio epidural lateral, que no se puede propagar lateralmente para descomprimirse. La sustancia de contraste se propaga, a través del camino de menor resistencia, hacia el lado opuesto. Puede 
Rev. Soc. Esp. del Dolor, Vol. 20, N. ${ }^{\circ}$ 1, Enero-Febrero 2013

aumentar la presión y derivar en una lesión isquémica de la médula espinal. Flexionar o rotar la cabeza y cuello puede abrir vías de escape laterales y liberar la presión a través de los forámenes neurales ensanchados.

$\mathrm{Al}$ igual que en el epidurograma caudal, se debe prestar atención a problemas de llenado. Es extremadamente importante que se observe propagación del contraste en dirección cefálica y caudal. Se debe evitar la localización del contraste en un área pequeña, pues esto puede incrementar significativamente la presión en el espacio epidural, y afectar la perfusión de la médula espinal. Se debe doblar el catéter como se describió para el abordaje caudal, e insértelo a través de la aguja. La abertura de la aguja se debe orientar hacia el lado que se pretende alcanzar. Se debe avanzar lentamente con el catéter hacia el canal lateral, y orientándolo en dirección cefálica. Se debe reorientar el catéter cuantas veces sea necesario, y cuando haya llegado al nivel deseado, se debe girar la punta del catéter hacia el foramen. Se inyecta 0,5 a $1 \mathrm{ml}$ de contraste para visualizar la raíz del nervio indicado. Se verifica que exista salida de contraste hacia fuera del foramen. Muy lentamente se infunde 150 unidades de Hylenex disuelto en $5 \mathrm{ml}$ de solución salina normal sin conservantes. A continuación, se adiciona 1 a $2 \mathrm{ml}$ de contraste y se observa si se abre la raíz del nervio previamente bloqueada por "cicatriz o fibrosis". Se recomienda hacer un test con $2 \mathrm{ml}$ de la dosis de $6 \mathrm{ml}$ de la solución de AL/E. En el Servicio de Racz se acostumbra a combinar $5 \mathrm{ml}$ de ropivacaína al $0,2 \%$ y $4 \mathrm{mg}$ de dexametasona. Si después de 5 minutos no se observan evidencias de propagación intratecal o intravascular, se inyecta los $4 \mathrm{ml}$ restantes. Se remueve la aguja, asegurando y recubriendo el catéter como ya se describió previamente. Si pasan 20 minutos desde la última dosis de solución AL/E y no se encuentran evidencias de un bloqueo subaracnoide o subdural, se comienza una infusión de $5 \mathrm{ml}$ de solución salina hipertónica en 30 minutos. Al terminar la infusión, se lava el catéter con 1 a 2 ml de solución salina normal sin conservantes y se venda.

La segunda y tercera infusión se hacen al día siguiente, con $6 \mathrm{ml}$ de ropivacaina al $0.2 \%$ sin dispersión, y $5 \mathrm{ml}$ de solución salina hipertónica, siguiendo la misma técnica y precauciones descriptas para la primera infusión. Se remueve el catéter, y se recetan antibióticos profilácticos. El seguimiento clínico dura 30 días.

\section{Lisis torácica de adherencias}

La técnica para entrar al espacio epidural torácico es idéntica a la usada en la región cervical. Se debe tener en cuenta la técnica 3-D. Asegurarse de tomar correctamente las imágenes laterales, al chequear la profundidad de la aguja. Esto se logra superponiendo las sombras de las costillas. El objetivo sigue siendo el espacio epidural ventrolateral, con la punta del catéter en el foramen del nivel buscado.
La principal diferencia entre la lisis torácica y la caudal o cervical es el volumen de las inyecciones. En este caso se utilizan $8 \mathrm{ml}$ de contraste, hilenex, AL/E y solución salina hipertónica.

\section{Deslizamiento o frotado mecánico neural}

El protocolo de la lisis de adherencias epidurales se ve favorecido por ejercicios de frotado neural, diseñados para movilizar las raíces de los nervios "haciéndolas deslizar" por el foramen. Así se remueve el tejido cicatrizal debilitado por la operación, y se previene nueva formación de tejido. Si estos ejercicios se repiten con constancia 3 o 4 veces al día durante algunos meses después de la operación, se disminuye significativamente la formación de tejido cicatricial. Es imprescindible que el Médico Experto en Medicina del Dolor trabaje en forma interdisciplinaria con Expertos en Fisiatría y Kinesiología.

\section{Mapeo epidural}

En pacientes con radiculopatía en múltiples niveles y dolores complejos, puede ser difícil determinar el principal origen del dolor. Se sugiere una técnica que se está utilizando en el Servicio de Racz, a la cual se ha llamado "mapeo", que localiza la raíz más dolorosa mediante estimulación, para luego realizar la operación a ese nivel. Existen muchas referencias en la literatura acerca del uso de la estimulación para confirmar la posición del catéter en el espacio epidural, y para localizar raíces nerviosas. Los catéteres TunL Kath y TunL-XL se pueden usar como estimuladores para identificar las raíces nerviosas.

Después de ingresar al espacio epidural, se avanza hacia dentro del espacio epidural ventrolateral, más allá del nivel deseado. Se debe asegurar que la punta del catéter esté orientada lateralmente hacia los forámenes, justo por debajo del pedículo. Se debe retraer el estilete del catéter aproximadamente $1 \mathrm{~cm}$. Usando pinzas tipo cocodrilo, se conecta el cátodo al estilete, y el ánodo en la aguja o en una plancha de tierra, o en una aguja calibre 22 insertada en la piel. Se aplica electricidad con un equipo estimulador, a una frecuencia de 50 pulsos por segundo, con un ancho de pulso de 450 milisegundos, aumentando la amplitud en incrementos pequeños (generalmente menos de 2-3 volts) hasta detectar una parestesia. Se debe preguntar al paciente si la parestesia se encuentra en el área donde normalmente siente mayor dolor. Se repite el proceso sucesivamente en cada nivel hasta reconocer la raíz del nervio que produce más dolor. Una vez identificada, se realiza la lisis en el nivel encontrado. Esta técnica de mapeo también es útil para identificar el lugar óptimo para la cirugía, antes de la primera intervención, o cuando ya se han practicado una o varias operaciones sin éxito. 
TABLA I. VOLÚMENES TÍPICOS PARA LISIS DE ADHERENCIAS

\begin{tabular}{|c|c|c|c|c|}
\hline & Contraste & $\begin{array}{l}\text { Hialuronidasa } \\
\text { y salina normal }\end{array}$ & $\begin{array}{l}\text { Anestésico local } \\
\text { y esteroide }\end{array}$ & $\begin{array}{l}\text { Solución salina } \\
\text { hipertónica al } 10 \%\end{array}$ \\
\hline Caudal & $10 \mathrm{ml}$ & $10 \mathrm{ml}$ & $10 \mathrm{ml}$ & $10 \mathrm{ml}$ \\
\hline $\begin{array}{l}\text { Caudal y } \\
\text { transforaminal }\end{array}$ & $5 \mathrm{ml}$ en cada catéter & $5 \mathrm{ml}$ en cada catéter & $5 \mathrm{ml}$ en cada catéter & $\begin{array}{l}8 \mathrm{ml} \text { en el catéter caudal } \\
\text { y } 4 \mathrm{ml} \text { en el catéter } \\
\text { transforaminal }\end{array}$ \\
\hline Torácico & $8 \mathrm{ml}$ & $8 \mathrm{ml}$ & $8 \mathrm{ml}$ & $8 \mathrm{ml}$ \\
\hline Cervical & $5 \mathrm{ml}$ & $6 \mathrm{ml}$ & $6 \mathrm{ml}$ & $5 \mathrm{ml}$ \\
\hline
\end{tabular}

\section{IMÁGENES TRANSFORMINALES}
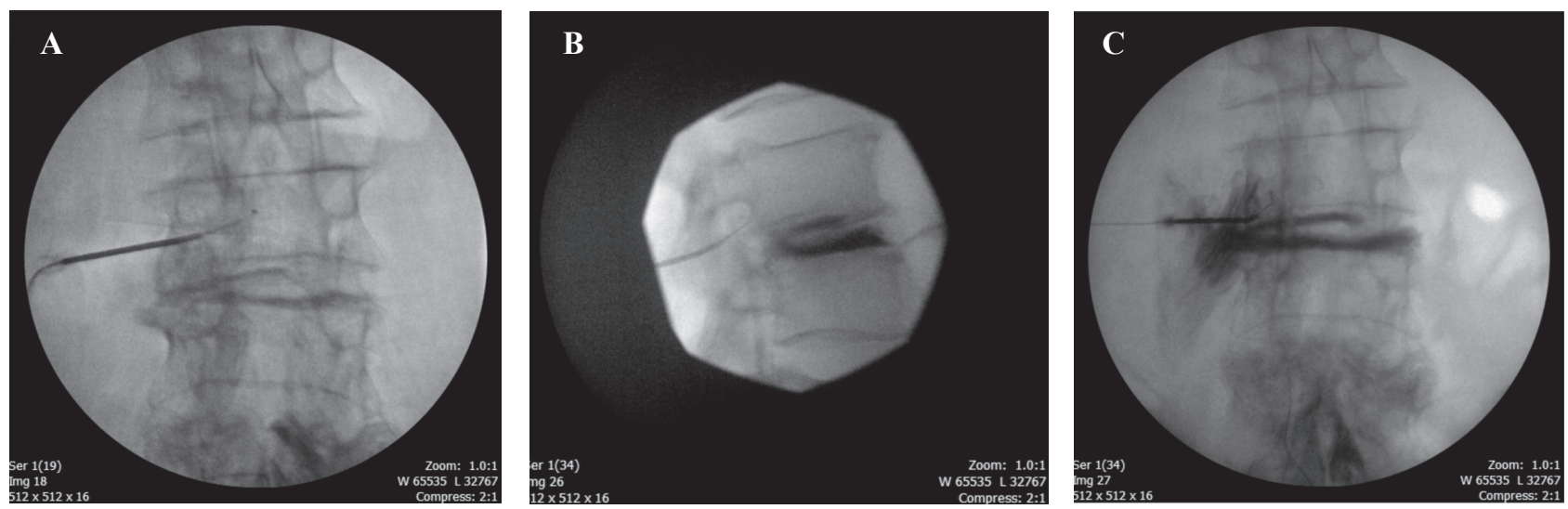

Fig. 1. A. Catéter transforaminal con la punta en posición medial al pedículo. B. Imagen Lateral transforaminal. C. A/P transforaminal que muestra tanto derrame epidural como intradiscal.

\section{IMÁGENES DE LISIS EPIDURAL CERVICAL}


Fig. 2. A. Lisis cervical con el catéter avanzado hasta el receso lateral. B. Catéter cervical más avanzado. 


\section{IMÁGENES DE LISIS POR VÍA CAUDAL}

Serie de Lisis caudal con epidurograma que muestra la ausencia de derrame bilateral en S2 antes de la lisis.
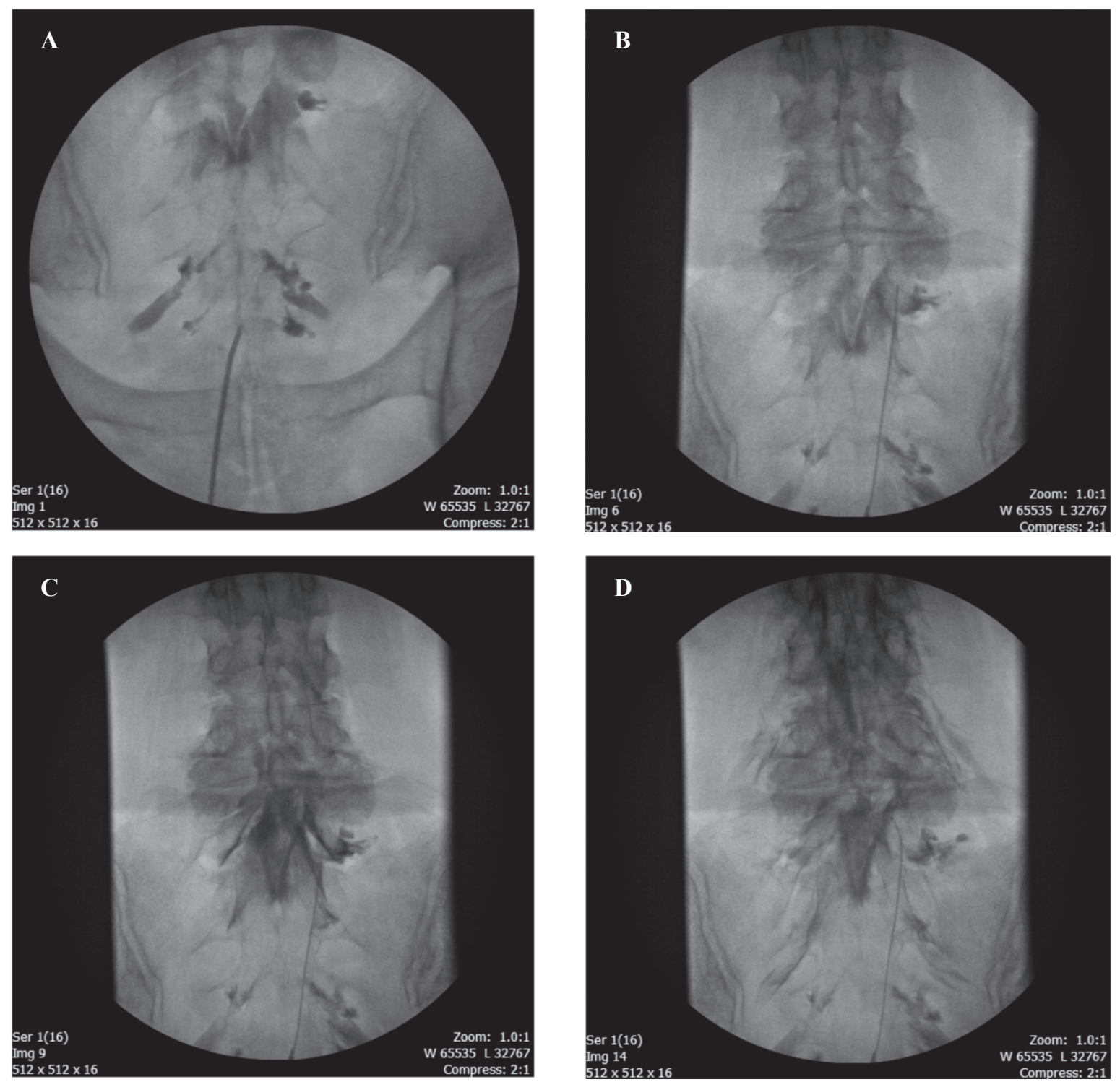

Fig. 3. A. Avance del catéter. B. Derrame de contraste para confirmación del catéter. C. Derrame de contraste que comienza a exhibir S2. D. Derrame de contraste en S2 casi completo. 


\section{IMÁGENES DE COMPLICACIONES}
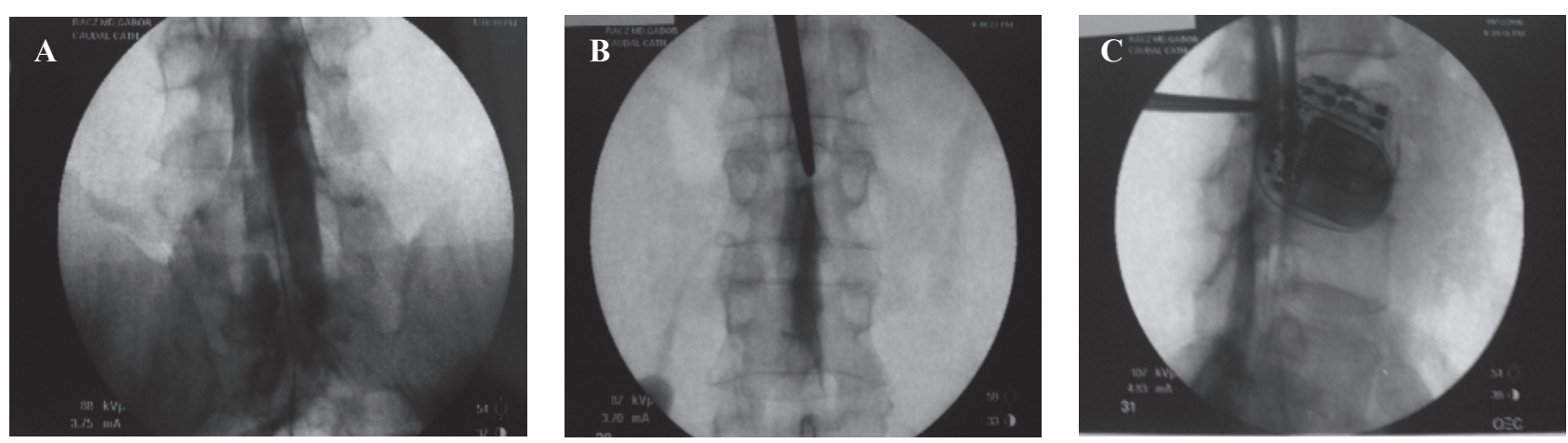

Fig. 4. A. Lisis caudal con el catéter que avanzó sobre la línea media y se introdujo en el espacio subdural. B. Aguja que avanzó en el canal con aspiración de $12 \mathrm{ml}$ de fluido. C. Vista lateral con inoculación subdural con avance de la aguja espinal para la descompresión.

\section{DIAGRAMAS DE ABORDAJE CAUDAL "PASO A PASO"}
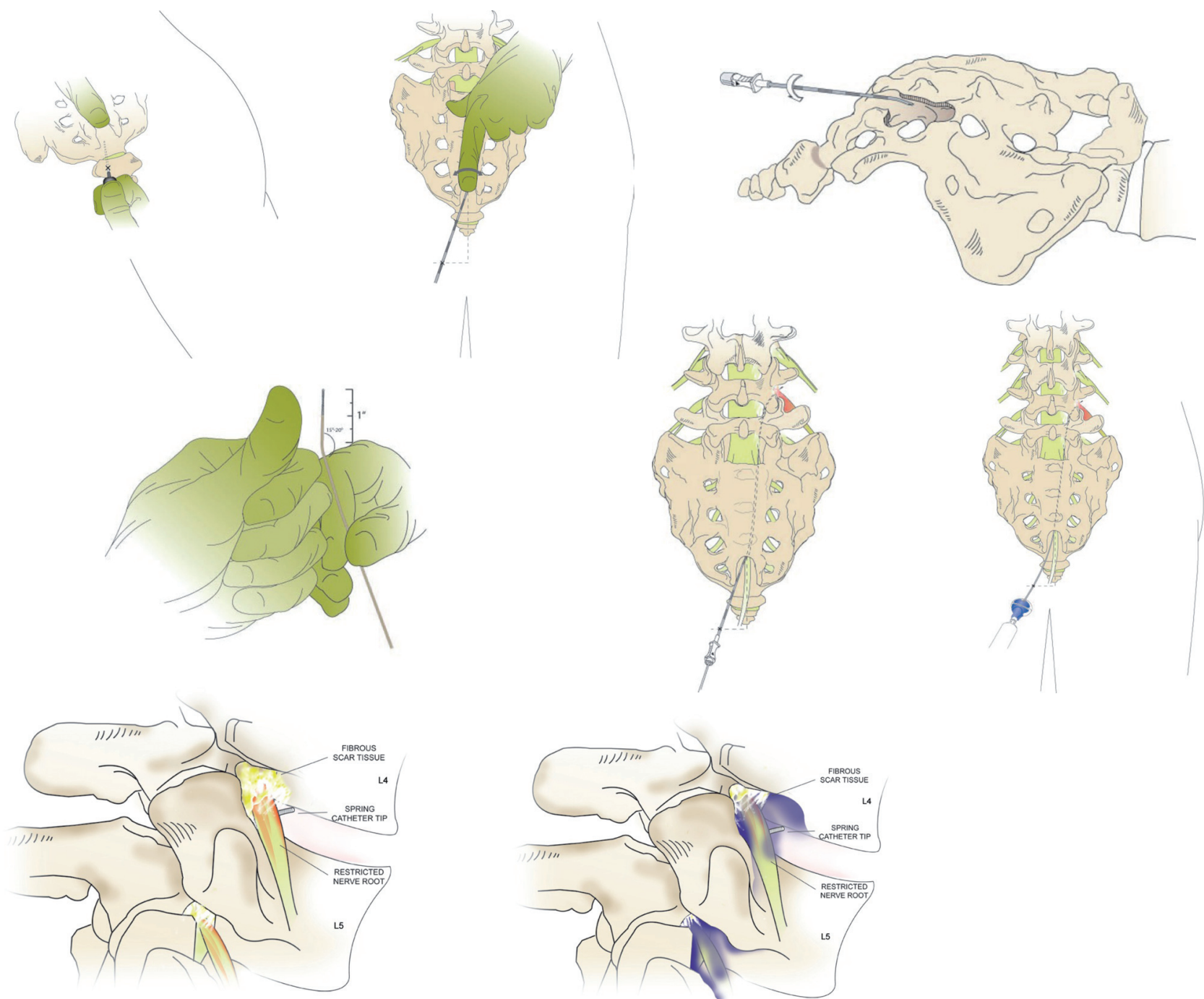

Fig. 5. 


\section{DIAGRAMAS DE LA TÉCNICA DE FROTAMIENTO NEURAL (NEURAL FLOSSING DIAGRAMS)}
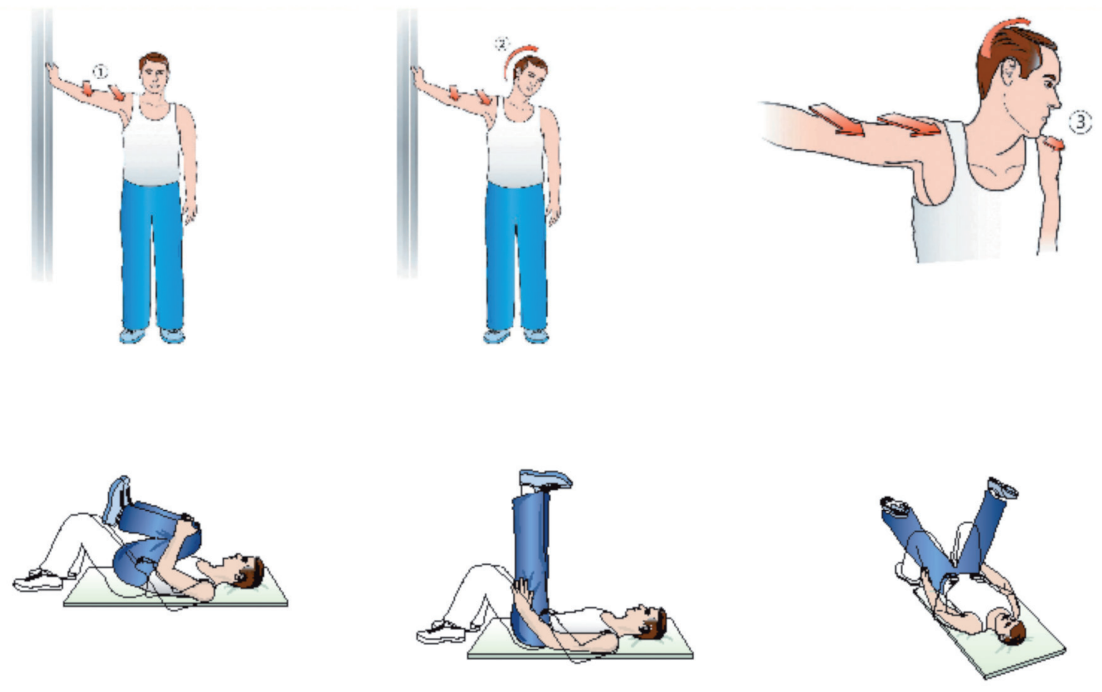

Fig. 6.

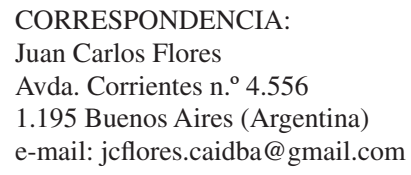

\section{BIBLIOGRAFÍA}

1. Omnipaque product insert. Princeton, NJ, Nycomed, Inc.

2. Isovue product insert. Princeton, NJ, Bracco Diagnostics, Inc.

3. Hypaque product insert. Princeton, NJ, Amersham Health, Inc.

4. Conray product insert. Phillipsburg, NJ, Mallinckrodt, Inct.

5. Racz G, Day M, Heavner J, et al. Hyaluronidase: a review of approved formulations, indications and off-label use in chronic pain management. Expert Opinion on Biological Therapy 2010;10(1):127-31.

6. Racz GB, Heavner JE: Cervical Spinal canal loculation and secondary ischemic cord injury-PVCS-perivenous counter spread-danger sign!! Pain Practice 2008;8(8):399-403.

7. Larkin T, Carragee E, Cohen S. A novel technique for delivery of epidural steroids and diagnosing the level of nerve root pathology. J Spinal Disord Tech 2003;16(2):186-92.

8. Racz GB, Sabonghy M, Gintautas J, et al. Intractable pain therapy using a new type of epidural catheter. JAMA. 1985; 248:579-80.

9. Sakai T, Aoki H, Hojo M, et al. Adhesiolysis and targeted steroid/local anesthetic injection during epiduroscopy alleviates pain and reduces sensory nerve dysfunction in patients with chronic sciatica. J Anesthesia. 2008;22(3):242-7.

10. Anderson S, Racz G, Heavner J. Evolution of epidural lysis of adhesions. Pain Physician 2000 Jul;3(3):262-70.

11. Racz G, Holubec J. Lysis of adhesions in the epidural space. In: Raj P (editor). Techniques of Neurolysis. Boson: Kluwer Academic; 1998. p. 57-72.

12. Arthur J, Racz G, et al. Epidural space: identification of filling defects and lysis of adhesions in the treatment of chronic painful conditions. bstracts of the 7th World Congress on Pain. Paris: IASP Publications; 1993.

13. Stolker R, Vervest A, Gerbrand J. The management of chronic spinal pain by blockades: a revew. Pain 1994;58:1-19.
14. Devulder J, Bogaert L, Castille F, et al. Relevance of epidurography and epidural adhesiolysis in chonic failed back surgery patients. Clin J Pain 1995; 11:147-50.

15. Racz G, Heavner J, In response to article by Drs. Devulder et al. Clin J Pain 1995;11:151-4.

16. Heavner J, Racz G, Raj P. Percutaneous epidural neuroplasty: prospective evaluation of $0.9 \%$ saline versus $10 \%$ saline with or without hyaluronidase. Reg Anesth Pain Med 1999;24:202-7.

17. Manchikanti L, Pakanati R, Bakhit C, et al. Role of adhesiolysis and hypertonic saline neurolysis in management of low back pain: evaluation of modification of the Racz protocol. Pain Digest 1999;9:91-6.

18. Manchikanti L, Pampati V, Fellow B, et al. Role of one day epidural adhesiolysis in management of chronic low back pain: a randomized clinical trial. Pain Phys 2001;4:153-66.

19. Manchikanti L, Rivera J, Pampati V, et al. One day lumbar adhesiolysis and hypertonic saline neurolysis in treatment of chronic low back pain: a randomized, double-blinded trial. Pain Phys 2004;7:177-86.

20. Manchikanti L, Cash K, McManus C, et al. The preliminary results of a comparative effectiveness of adhesiolysis and caudal epidural injections in managing chronic low back pain secondary to spinal stenosis. Pain Phys 2009 NovDec;12(6):E341-54.

21. Manchikanti L, Singh V, Cash K, et al. A comparative effectiveness evaluation of percutaneous adhesiolysis and epidural steroid injections in managing lumbar post surgery syndrome. Pain Phys 2009 Nov-Dec;12(6):E355-68.

22. Veihelmann A, Devens C, Trouiller H, et al. Epidural neuroplasty versus physiotherapy to relieve pain in patients with sciatica: a prospective randomized blinded clinical trial. J Orthop Sci 2006;11:5-369.

23. Gerdesmeyer L, Lampe R, Veihelmann A, et al. Chronic radiculopathy. Use of minimally invasive percutaneous epidural neurolysis according to Racz. Der Schmerz. 2005; 19:285-95.

24. Gerdesmeyer L, Rechl H, Wagenpfeil S, Ulmer M, Lampe R, Wagner K. Minimally invasive epidural neurolysis in chronic radiculopathy. A prospective controlled study to prove effectiveness. Der Orhopade. 2003;32:869-76.

25. Trinidad JM, Torres LM. Epidurolisis o adhesiolisis lumbar: técnica de Racz. Rev Soc Esp Dolor 2011;18(1):65-71. 